frequencies has proved of the greatest value in this connexion. One of the earliest applications was to police work, and this has proved of great value in preventing crime and arresting eriminals.

\section{Tuberculosis in Tunisia}

Is his inaugural thesis (Thèse de Paris, No. 365 ; 1938), Dr. M. H. Thamer states that in Tunisia, which is a country of $2,608,313$ inhabitants with a mixed population consisting mainly of Tunisian Mussulmans $(2,335,623)$ with Tunisian Jew's $(59,485)$ and Europeans $(213,205)$, the mortality from tuberculosis is much higher among the Mussulmans than in the other two groups. In Tunis alone there are about 4,000 tuberculous Mussulmans, and tuberculosis alone is responsible for more than a third of all the deaths from epidemic diseases. Further proof of the high incidence of tuberculosis among Mussulmans is furnished by army statistics, according to which 0.59 per cent of the Mussulman soldiers are affected as compared with 0.25 per cent of the Europeans. Moreover, all the Tunisian practitioners are agreed that the number of tuberculous subjects is increasing yearly in enormous proportions, and that the immense majority of the cases are highly infectious and run a rapidly fatal course. At the present time, the means for combating tuberculosis in Tunisia are quite inadequate. The only institution for detecting cases is the Mussulman Dispensary at Tunis, while barely 84 beds are available for all the cases of pulmonary tuberculosis in a population of more than two millions, among whom there are more than 6,000 deaths from tuberculosis yearly. There are at present no institutions in Tunisia for the prevention of tuberculosis among Mussulman children. The following measures, according to Dr. Thamer, are urgently required: (1) for children, the creation of open-air schools, holiday colonies and a preventorium; (2) for adults, the establishment of five sanitary districts for Tunis, Susa, Sfax, Ket and Bizerta respectively, in each of which there should be a tuberculosis dispensary and the provision of about fifty hospital beds; (3) there should also be a sanatorium of about a hundred beds in the suburbs of Tunis; (4) afterwards the antituberculosis campaign should be extended to the smaller towns and the rural districts which constitute about three quarters of the total population of the country.

\section{Government Scientific Publications}

Most scientific workers are aware that from time to time research papers of immediate interest to them in their own particular work appear among Govern. ment publications. Even to those who make the fullest and most regular use of such publications, the admirably written and printed "Brief Guide to Government Publications" which has recently been issued by H.M. Stationery Office will probably come as a revelation of the extent and importance of the contribution to scientific, industrial and agricultural research which comes from such sources. Whether in agriculture, economics or social questions, education, medicine and public health, transport and com. munications, science, industry and technology, H.M.
Stationery Office not only supplies innumerable publications containing up-to-date information on specialized subjects, but is also to an increasing extent the channel through which the results of both pure and applied research are published. A very lucid but comprehensive description of the chief Government publications in all these fields as well as in others of less direct interest to scientific workers is contained in this useful guide, and not the least of its merits are the brief but clear accounts of how Government publications are sold and of the cata. logues, lists and bibliographies of such publications which are available.

\section{Research on Coal Utilization}

THE British Coal Utilisation Research Association has decided to establish an experimental station in London. Premises have been secured at West Brompton, and are now being equipped. Dr. D. H. Bangham, lately professor of chemistry and dean of the Faculty of Science, Egyptian University, Cairo, who has made important contributions to the physical chemistry of charcoal, cellulose and other carbonaceous materials, has been appointed the senior member of the scientific staff, and will take charge of a group of programmes connected with the use of coal. Mr. J. S. Hales, who will take charge of the Domestic Appliances Department, has worked at the Fuel Research Station on the measurement of smoke and the operation of coke fires, and has since served on the research staff of a manufacturer of domestic solid fuel burming appliances. Mr. R. T. Hancock, formerly associate editor and contributor to "Kemp's Engineers Handbook.", has been appointed head of the Intelligence Department and editor of the Association's monthly bulletin.

\section{An Electrodeposition Exhibit}

MANY examples of the varied applications of electrodeposition were shown at a special exhibition held at the Science Museum, London, in 1935. The success of this exhibition prompted the arrangement of a smaller permanent exhibit, which has been generously presented by the Electrodepositors' Technical Society. The main features of the original exhibition have been incorporated in a single case, which is now on view in the Chemistry Collections of the Science Museum. One of the most interesting sections of the exhibit deals with research, and has been arranged by the Research Department, Woolwich. Here may be seen the results of the systematic studies of electrodeposition problems made at Woolwich and elsewhere during the past twenty years.

\section{Crystals, Molecules and Atoms}

IN a review which appeared in NATURE of September 10, p. 455, of the second volume, entitled "The Fine Structure of Matter", of Dr. C. H. Douglas Clark's treatise on atomic and molecular structure, reference was made to the omission of modern quantum theory from Part 3, entitled "The Quantum 